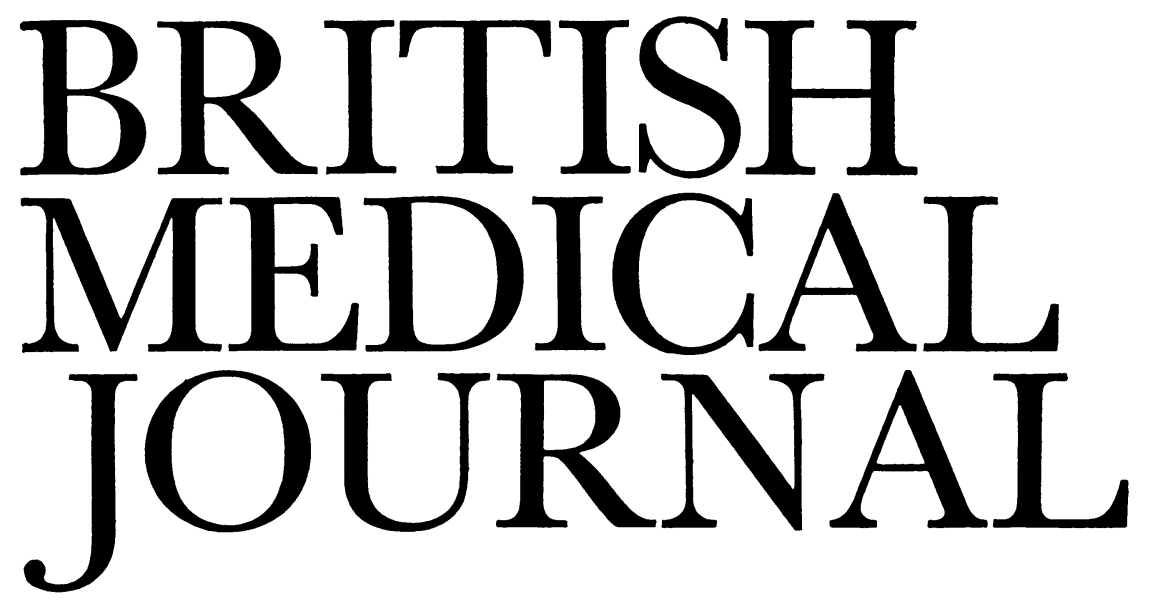

LONDON, SATURDAY 14 MARCH 1981

\title{
Gastric ulcer: benign or malign?
}

A prerequisite for the proper understanding of ulcerating lesions in the stomach is agreement about the terms used. Apart from mucosal ulcers or gastric erosions, there are four main categories: chronic benign peptic ulcer-the familiar gastric ulcer; ulcerating carcinoma; coexisting carcinoma and gastric ulcer; and ulcer-cancer. By ulcerating carcinoma we mean a large necrotic tumour whose surface has ulcerated. The circumstances in which a peptic ulcer and small carcinoma not only coexist but are contiguous are particularly important. Such combined lesions probably begin as small mucosal carcinomas. Part of the localised carcinoma then ulcerates, or alternatively a peptic ulcer may begin in the adjacent gastric mucosa. Whatever its evolution, it is the peptic ulcer that is likely to produce symptoms. The size of the peptic component is usually much larger than that of the cancer, which is commonly detectable only microscopically. The term ulcercancer is best reserved for a carcinoma that has developed from a benign gastric ulcer. Such transformation was considered quite common until Newcomb's detailed study ${ }^{1}$ of the histological changes. Neoplastic change occurring in a benign gastric ulcer is now thought to be exceedingly rare-indeed, some authorities deny that it occurs.

In mythology a chimaera was a monster made from parts of different animals. The coexistent carcinoma and gastric ulcer are of such a nature. The neoplastic component may remain small and confined to the gastric mucosa for months or years, but ultimately it is likely to be invasive. Recognition of the double nature of the lesion at an early stage is vital for the patient. How can this best be achieved ? Despite its limitations, the barium meal is quick, convenient, devoid of hazard, and usually remarkably helpful; it remains the primary investigation for patients with dyspepsia. But it must now be regarded as a curtain raiser, a prelude to endoscopic examination, whenever there is any suspicion of an ulcerating lesion in the stomach.

The "fibreoptician" has been able to add sampling of the tissues and cells of gastric lesions to visual inspection for a little over a decade. A recent report ${ }^{2}$ from the endoscopy unit of the Bristol Royal Infirmary shows the change in practice that has resulted. In a three-year retrospective analysis of 265 patients referred with ulcerating lesions in the stomach and followed for two years, $37(14 \%)$ were found to show evidence of malignancy. The implications of such a study should not be confused with conclusions derived from earlier analyses of the diagnostic success of radiological examination alone. To quote two, in Britain ${ }^{3} 5 \%$ and in the United States ${ }^{4} 3.9 \%$ of patients considered to have benign ulcers proved eventually to have carcinomas when later followed for several years. Radiological examinations by less careful and experienced radiologists might have resulted in more errors. In the past few years, since endoscopy has become widely available, some radiologists have become hesitant to vouchsafe a firm opinion on the nature of gastric ulcers.

In the Bristol series the histological evidence provided by endoscopic biopsy specimens proved reliable. These results were achieved by taking multiple samples, but serial examinations were sometimes required. A study in Glasgow ${ }^{5}$ emphasised the value of aimed brushings to obtain cytological material as an adjunct to biopsy specimens. The method proved very reliable but, as with all cytological approaches, optimum sensitivity and specificity were possible only with adequate sampling, a variety of collection methods, and scrupulous care in technique.

Cimetidine has now established the new era of antisecretory treatment for peptic ulceration. Such treatment may inevitably have a masking effect on symptoms if the drug is used before adequate diagnosis has been established. Healing of the peptic component is likely to abolish symptoms in patients with coexisting ulcer and carcinoma, and the carcinoma may remain clinically latent for months or perhaps even years. To impugn cimetidine as a carcinogen ${ }^{6}$ as a result of such cases is misleading and unfair to patients. Possibly continuous longterm treatment with antisecretory drugs may prove to have unexpected adverse consequences. Such considerations need to be distinguished from the requirement for diagnostic precision. Cicero's aphorism remains true": "A careful physician, before he attempts to administer a remedy to his patient, must investigate the malady of the man he wishes to cure."

\footnotetext{
${ }^{1}$ Newcomb ED. The relationship between peptic ulceration and gastric carcinoma. Brf Surg 1932;20:279-308

2 Mountford RA, Brown P, Salmon PR, Alvarenga C, Neumann CJ, Read AE. Gastric cancer detection in gastric ulcer disease. Gut 1980;21 :9-17.

${ }^{3}$ Montgomery RD, Richardson BP. Gastric ulcer and cancer. $Q \mathcal{F}$ Med 1975;44:591-9.

4 Grossman MI. Resumé and comment. Gastroenterology $1971 ; 61: 635-40$.

5 Young JA, Hughes HE. 3-year trial of endoscopic cytology of the stomach and duodenum. Gut $1980 ; 21: 241-6$.

${ }^{6}$ Anonymous. Cimetidine and gastric cancer. Lancet 1979;i:1013.

${ }^{7}$ Rubin P. Gastric cancer in patients who have taken cimetidine. Lancet $1979 ; \mathrm{i}: 1236$.
} 